\title{
Fabrication of Nano-Yttria Dispersed Duplex and Ferritic Stainless Steels by Planetary Milling Followed by Spark Plasma Sintering and Non-Lubricated Sliding Wear Behaviour Study
}

\author{
Rajendrachari Shashanka ${ }^{1}$, Debasis Chaira ${ }^{1 *}$ and Dibyendu Chakravarty ${ }^{2}$ \\ 1. Department of Metallurgical and Materials Engineering, National Institute of Technology Rourkela-769008, India \\ 2. International Advanced Research Centre for Powder Metallurgy and New Materials, Balapur, Hyderabad-500005, India
}

\begin{abstract}
We report an efficient method of fabrication of nano-yttria dispersed duplex and ferritic stainless steels by planetary milling of elemental $\mathrm{Fe}, \mathrm{Cr}$ and Ni powders and their consolidation by spark plasma sintering (SPS). It has been found that addition of yttria nanoparticles not only increases the density, hardness, wear resistance and compressive strength of stainless steels, but also initiates $\alpha$-Fe to $\gamma$-Fe phase transformation. The non-lubricated sliding wear mechanisms of yttria dispersed and yttria free stainless steels against diamond indenter are mainly abrasive with slight oxidative mechanism. The oxidative mechanism is confirmed by energy dispersive spectroscopy analysis of worn surface and wear debris. Maximum compressive stress of yttria dispersed duplex stainless steels was found to be 1,205 MPa and yield stress of $821 \mathrm{MPa}$.
\end{abstract}

Key words: Stainless steel, spark plasma sintering (SPS), nano-structured, non-lubricated sliding wear, yttria.

\section{Introduction}

Duplex stainless steel is the important grade of stainless steel composed of almost equal proportions of austenite and ferrite phases. The combining effect of these two phases impart high mechanical strength, low thermal expansion, good weldability, better corrosion resistance, high temperature tensile and creep strength, good fatigue resistance, high energy absorption, abrasion and erosion resistance [1, 2]. Therefore, duplex stainless steel is mainly used in pulp and paper industries, de-salination plants, construction of bridges, flue gas cleaning, heat exchangers, nuclear and chemical industries, structural design components, storage tanks, pressure vessels, rotor, impellers and shafts [3-5]. These steels are also used in electro chemical investigation of bioactive

*Corresponding author: Dr. Debasis Chaira, assistant professor, research fields: powder metallurgy, nano-structured materials and mechanical alloying. molecules such as folic acid [6]. On the other hand, ferritic stainless steels are non hardenable stainless steels having BCC structure and exhibits high thermal conductivity, creep resistance, magnetic property, corrosion resistance, high yield strength and splendid high temperature oxidation resistance [7]. The above properties of ferritic stainless steel made this grade to use mainly in water treatment plants, electric cabinets, cold water tanks, storing knives, surgical instruments, refrigeration cabinets and other metallic implements. Both duplex and ferritic stainless steels are having very wide range of applications due to their excellent properties and these properties can be further improved by bringing down their structure to nano level $(<100 \mathrm{~nm})$ or ultrafine level $(100$ to $1,000 \mathrm{~nm})$ or by adding metal oxide dispersing agents. These dispersing agents or inter-metallic phases act as obstacles for dislocation motion and increases the strength of the matrix $[8,9]$. The metal oxide 
dispersoid such as nano- $\mathrm{Y}_{2} \mathrm{O}_{3}$ imparts more strength to interfacial bonding in stainless steel, hinders grain growth and increases the hardness of the stainless steels [10-13].

Therefore, we prepared nano-structured duplex and ferritic stainless steel powders by milling elemental $\mathrm{Fe}, \mathrm{Cr}$ and Ni powders for $10 \mathrm{~h}$ in a specially designed dual drive planetary mill (DDPM). The detail investigation of duplex and ferritic stainless steel preparation, mill fabrication and design were reported by the authors in their previous publication [14]. High energy planetary milling involves in the production of extremely refined materials in large amount at preferably shorter time at reduced possibility of oxidation. Olaniran et al. [15] reported that particle size ratio plays an important role in densification kinetics. Materials with nano-structure improve the density, hardness, wear resistance and compressive strength.

The consolidation of nano-structured materials by conventional sintering is restricted due to their poor strength, poor density and also inability to retain nanostructure after sintering. On the other hand, spark plasma sintering (SPS) is one of the best and advanced sintering techniques that can hinders grain growth during consolidation and also fabricates poorly sinterable materials. The SPS process involves simultaneous application of load as well as heat on the materials to be sintered. SPS is a short time process having many advantages over conventional sintering methods [16-18]. It involves discharging of spark plasma at gaps of the particles with an on-off electrical current [19] and induces neck formation, thermal diffusion process on the particles. This results in hindered grain growth, efficient shrinkage in less time and cleaner grain boundaries for effective interface formation [20].

Wei et al. prepared nano-crystalline 430L stainless steel by QM-1SP4 planetary ball mill. The milling was performed for $20 \mathrm{~h}$ with ball to powder weight ratio of $20: 1$ and mill speed of $250 \mathrm{rpm}$.
Consolidation of stainless steel powders were performed by SPS at 800,900 and $1,000{ }^{\circ} \mathrm{C}$ sintering temperatures with different holding times $(5,10$ and $15 \mathrm{~min})$. They investigated the effect of different sintering temperatures and holding time on the microstructure, density, hardness and yield strength of 430L stainless steel. They reported that increase in sintering temperature increases the density and hardness but the tensile strength reaches a maximum value of $713 \mathrm{MPa}$ at $900{ }^{\circ} \mathrm{C}$ and it eventually decreases with further increase in sintering temperature due to grain growth [21]. Allahar et al. synthesized $\mathrm{Fe}-16 \mathrm{Cr}-3 \mathrm{Al}-0.5 \mathrm{Y}_{2} \mathrm{O}_{3}$ and Fe-16Cr-3Al- $0.5 \mathrm{Y}_{2} \mathrm{O}_{3}-1 \mathrm{Ti}$ powders by mechanical alloying in a Retsch planetary ball mill for $20 \mathrm{~h}$ and 40 $\mathrm{h}$ with a constant mill speed of $380 \mathrm{rpm}$ and ball to powder weight ratio of $10: 1$. The prepared powders were sintered by spark plasma sintering method at 950,1000 and $1,050{ }^{\circ} \mathrm{C}$ using pressure of $80 \mathrm{MPa}$ with different holding times (0, 30 and $60 \mathrm{~min})$. They reported greater density and hardness for Fe-16Cr-3Al-0.5 $\mathrm{Y}_{2} \mathrm{O}_{3}-1 \mathrm{Ti}$ consolidated samples than $\mathrm{Fe}-16 \mathrm{Cr}-3 \mathrm{Al}-0.5 \mathrm{Y}_{2} \mathrm{O}_{3}$ samples due to the addition of $\mathrm{Y}-\mathrm{O}-\mathrm{Ti}$ nanoclusters. The addition of Y-O-Ti reduces the grain growth to higher extent than Ti free stainless steel samples [22]. Xia et al. prepared $16 \mathrm{Cr}-5 \mathrm{Al}$ oxide dispersion strengthened (ODS) ferritic steel by mechanical alloying consolidated by SPS at $1,050^{\circ} \mathrm{C}$ and pressure of $45 \mathrm{MPa}$ for $5 \mathrm{~min}$. They found that fabricated $16 \mathrm{Cr}-5 \mathrm{Al}$ ODS ferritic steel exhibits better oxidation resistance than $\mathrm{Al}$ free ODS ferritic stainless steel and commercial 304 stainless steel. They reported the improved oxidation resistance of $16 \mathrm{Cr}-5 \mathrm{Al}$ ODS ferritic steel is due to the formation of continuous and thick $\mathrm{Al}_{2} \mathrm{O}_{3}$ film on the surface [23].

From the available literatures it has been found that prolong milling is essential for the synthesis of stainless steel in planetary mill. In the present paper, duplex (Fe-18Cr-13Ni) and ferritic stainless steel (Fe-17Cr-1Ni) powders were prepared by planetary milling for only $10 \mathrm{~h}$ and then consolidation by SPS. 

Followed by Spark Plasma Sintering and Non-Lubricated Sliding Wear Behaviour Study

In another set, $1 \mathrm{wt} . \%$ of yttria nanoparticles were mixed with duplex and ferritic stainless steel separately by using turbula shaker mixer for $3 \mathrm{~h}$ and then consolidated by SPS method. Our aim is to study the effect of yttria addition on the phase transformation, density, hardness, wear resistance and compressive strength of SPS consolidated duplex and ferritic stainless steel samples.

\section{Experimental}

The preparation of nano-structured duplex (Fe-18Cr-13Ni) and ferritic stainless steel (Fe-17Cr-1Ni) powder by specially designed dual drive planetary milling was reported by the authors in their previous papers $[1,24]$. Figs. $1 \mathrm{a}$ and $1 \mathrm{~b}$ show the SEM microstructures of $10 \mathrm{~h}$ milled duplex and ferritic stainless steel powders. It indicates that particles are irregular in shape and average size of around $5 \mu \mathrm{m}$ to $10 \mu \mathrm{m}$ in both cases. Fig. 1c depicts the micrograph of as received spherical $\mathrm{Y}_{2} \mathrm{O}_{3}$ nanoparticles of average size around $40 \mathrm{~nm}$.

The milled duplex and ferritic stainless steel powders were mixed with 1 wt. $\% \mathrm{Y}_{2} \mathrm{O}_{3}$ nanoparticles in a turbula shaker mixer (TURBULA ${ }^{\circledR}$ T2F, Willy A. Bachofen AG Maschinenfabrik, Switzerland) for 3 hours. Yttria dispersed and yttria free duplex and ferritic stainless steel powder samples were consolidated by SPS (SCM 1050, Sumitomo Coal Mining Co, Ltd Japan) at a pressure of $50 \mathrm{MPa}$ and $1,000{ }^{\circ} \mathrm{C}$ for $5 \mathrm{~min}$ in a $20 \mathrm{~mm}$ diameter graphite die. All the consolidated stainless steel samples were polished carefully for further investigation. The density, microhardness of yttria dispersed and yttria free stainless steels were measured by Archimedes method [25] and Vickers microhardness methods respectively. Vickers microhardness studies were performed by using LECO-LM248AT fitted with Vickers pyramidal diamond intender. The Microstructural studies were carried out using Carl Zeiss optical microscopy and FEI NANO NOVA 450 field emission scanning electron microscopy (FESEM). The phase fractions of all the SPS stainless steels were calculated by using Axio Vision Release 4.8.2 SP3 (08-2013) software. The consolidated stainless steel samples were characterized by X-ray diffraction (XRD) in a Philips PANalytical diffractometer using filtered $\mathrm{Cu}$ K $\alpha$-radiation $(\lambda=$ $0.1542 \mathrm{~nm}$ ). Compression tests were performed at $1 \mathrm{~mm} / \mathrm{min}$ strain rate using Instron SATEC KN600 at room temperature.

The non-lubricated sliding wear studies of consolidated stainless steels were performed in pin-on disc wear tester (Ducom, TR-208 M1) where Rockwell diamond indenter rotates at $20 \mathrm{rpm}$ with a speed of $0.0041 \mathrm{~m} / \mathrm{s}$ for $15 \mathrm{~min}$ against stainless steel samples at room temperature and a relative humidity of $70 \%$. All the wear studies were performed at applied loads of $40 \mathrm{~N}$ and $60 \mathrm{~N}$ with track radius of $2 \mathrm{~mm}$. During each wear test, the diamond indenter was cleaned ultrasonically and dried and all the wear tests were performed 3-4 times to obtain reproducible values. Wear mechanism was studied by investigating the wear track and wear debris morphology by using JEOL JSM-6084LV scanning electron microscopy. The schematic diagram of wear set up is shown in Fig. 2.
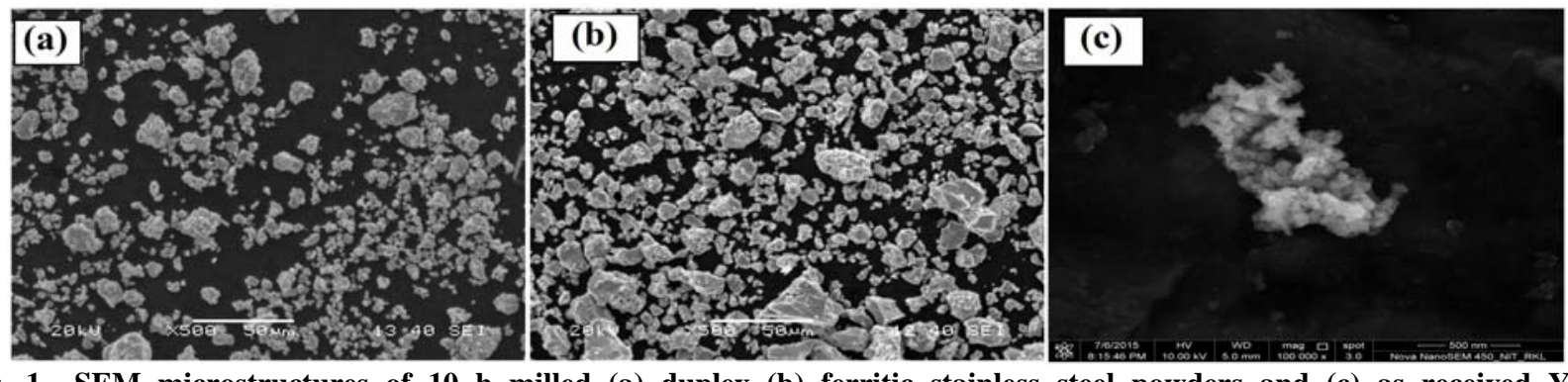

Fig. 1 SEM microstructures of $10 \mathrm{~h}$ milled (a) duplex (b) ferritic stainless steel powders and (c) as received $\mathrm{Y}_{2} \mathrm{O}_{3}$ nanoparticles. 

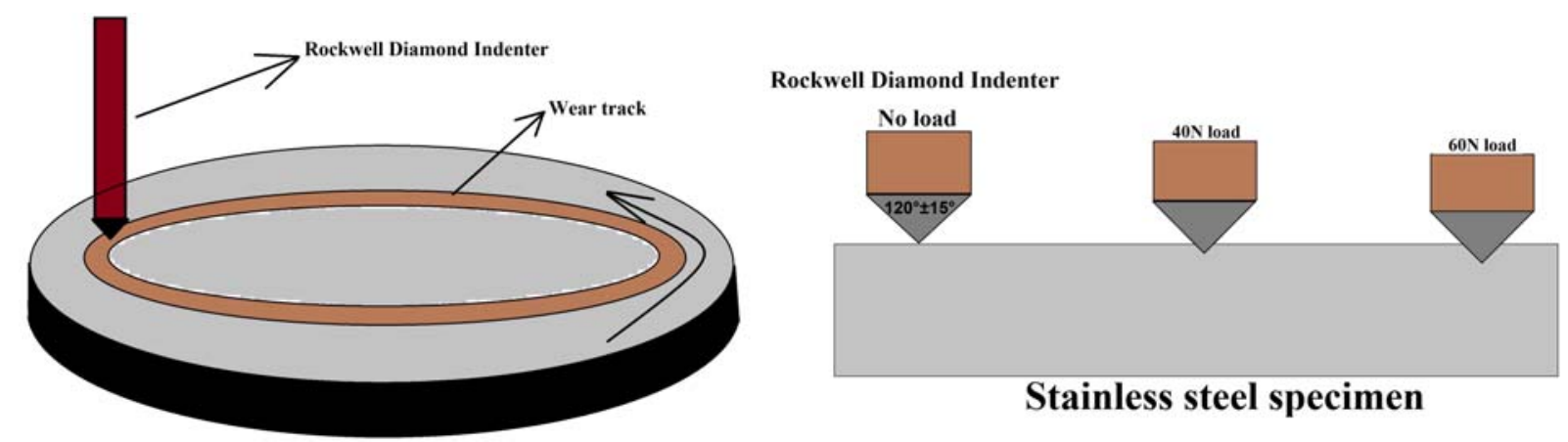

Stainless steel specimen

Fig. 2 The schematic diagram of wear set up.
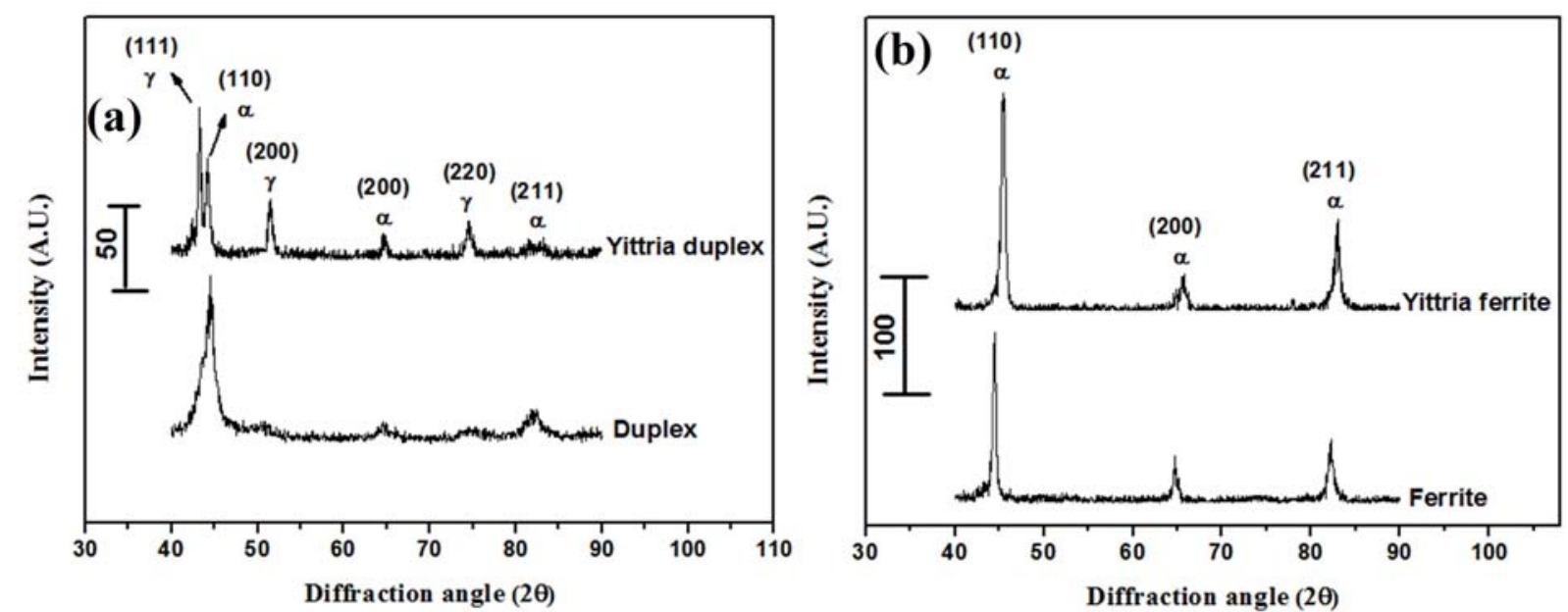

Fig. 3 XRD spectra of (a) duplex and yttria dispersed duplex (b) ferritic and yttria dispersed ferritic stainless steel samples sintered at $1,000{ }^{\circ} \mathrm{C}$ by SPS.

\section{Results and Discussion}

\subsection{Phase Analysis by XRD}

Figs. $3 \mathrm{a}$ and $3 \mathrm{~b}$ represent the XRD spectra of duplex, yttria dispersed duplex, ferritic and yttria dispersed ferritic stainless steel samples sintered at $1,000{ }^{\circ} \mathrm{C}$ by SPS method respectively. From Fig. 3a, it is observed that XRD peaks of duplex steels are broad, whereas peaks are sharp in case of yttria dispersed duplex steel. It has also been found that all peaks are ferritic in case of duplex steel but after addition of nano-yttria, strong austenite peaks are present along with ferritic peaks. This phase transformation is due to the nano crystallite size of SPS stainless steel and also due to the addition of yttria nanoparticles. The added $\mathrm{Y}_{2} \mathrm{O}_{3}$ nanoparticles goes in to the smaller interstitial sites of ferrite crystallites and forms a mismatch strain and induces the phase transformation from $\alpha$-Fe to
$\gamma$-Fe. The refinement of ferrite crystallite to nano level can also initiate phase transformation. However, in case of both ferritic and yttria dispersed ferritic steel, all peaks are ferritic (Fig. 3b).

It should also be noted that the stainless steel powder has undergone many transformations like amorphization, increase in volume fraction of grain boundaries, introduction of structural defects, refinement of crystallite size; And this increase the number of defect storage sites, shorter diffusion paths and attains non-equilibrium state during milling [14, 26]. There are no traces of secondary phases like sigma phase; carbides or nitrides precipitated diffraction peaks in all the stainless steel samples.

\subsection{Microstructure and Phase Analysis}

Fig. 4 shows the optical microstructures of yttria free and yttria dispersed ferritic and duplex stainless 
steel samples respectively consolidated at $1,000{ }^{\circ} \mathrm{C}$ by SPS method. From the optical micrographs it is confirmed that, yttria dispersed stainless steel forms less pores than yttria free duplex stainless steel. Tiwari et al. [27] reported that the added nano yttria not only diffuses in to interstitial sites of duplex stainless steel but also to the grain boundary. This increases the densification process in yttria dispersed duplex stainless steel by grain boundary strengthening. This decreases the porosity ratios and hinders the grain size. The optical microstructure of yttria dispersed ferritic stainless steel shows small, spherical grains with less porosity as shown in Fig. 4b. On the other hand, microstructure of yttria free ferritic stainless steel depicts large spherical grains with more pores as shown in Fig. 4a. The duplex and yttria dispersed duplex stainless steels contain acicular ferrite as shown in Figs. 4c and 4d respectively. The acicular ferrite is characterized by needle shaped chaotic grains of ferrite usually formed in the interior of austenite phase by nucleation on the inclusion. This chaotic order acts as obstacles for cleavage, crack propagation and hence increases the strength of stainless steel [28]. Ricks et al. [29] reported that dispersion of oxygen rich non-metallic inclusions results in the formation of acicular ferrites. In the present investigation, we dispersed non-metallic dispersoids like $\mathrm{Y}_{2} \mathrm{O}_{3}$ nanoparticles into stainless steel, as a result of which more acicular ferrites were formed in yttria dispersed duplex stainless steel than yttria free duplex stainless steel. Usually acicular ferrites are formed at the interior grains of pure austenite and hence ferritic and yttria dispersed ferritic stainless steels do not exhibit acicular ferrites. The effect of yttria on phase transformation from $\alpha-\gamma$ is well supported by both XRD study (Fig. 3) and microstructure analysis (Figs. $4 \mathrm{c}$ and $4 \mathrm{~d}$ ). The addition of yttria increases the amount of austenite phase in both duplex and yttria dispersed duplex stainless steels as shown in the figure. Therefore, we performed phase analysis by calculating volume fraction of both ferrite and austenite phases by using Axio Vision Release software. Figs. 4e and $4 \mathrm{f}$ represent the phase analysis study of duplex and yttria dispersed duplex stainless steel respectively. Yttria dispersed duplex stainless steel contains $71 \%$ volume fraction of austenite; whereas duplex stainless steel contains $58 \%$ of austenite.

\subsection{Density and Hardness Study}

Fig. 5a depicts the densities of duplex, ferritic, yttria dispersed duplex and yttria dispersed ferritic stainless samples sintered by SPS method. The percentage density of duplex and ferritic stainless steel sintered by SPS method is $91 \%$ and $92 \%$ respectively. Similarly, yttria dispersed duplex and ferritic stainless steel possess density of $93 \%$ and $95 \%$ respectively. Spark plasma sintered stainless steel samples comprise of ultrafine or nano crystalline materials [30]. Therefore, SPS stainless steels show more density and hardness than conventionally sintered stainless steel samples [31]. Tiwari et al. [27] reported that density, hardness and tribological properties of ferritic (434L) stainless steel can be improved by adding yttrium aluminium garnet (YAG). They concluded that addition of $10 \mathrm{wt} . \%$ YAG results in weak YAG-YAG bonding instead of strong YAG-stainless steel bonding and agglomerates at grain boundaries to reduce the hardness of stainless steel. However, addition of small amount of YAG (5 wt.\%) results in strong YAG-stainless steel bonding.

Fig. $5 \mathrm{~b}$ represents the effect of indentation load on the microhardness of yttria dispersed and yttria free duplex and ferritic stainless steel sintered at $1,000{ }^{\circ} \mathrm{C}$ by SPS. The Vickers microhardness measurements were carried out at 10, 25 and $50 \mathrm{gf}$ indentation load. At least 5 trials of indentations were made at each load and the average values of the diagonal lengths of indentation marks were measured as hardness for each stainless steel sample. From the figure it is clear that Vickers microhardness value decreases with increase in indentation load due to indentation size effect (ISE) $[31,32]$. ISE occurs due to the some intrinsic structural 

Followed by Spark Plasma Sintering and Non-Lubricated Sliding Wear Behaviour Study

factors such as indentation elastic recovery, work hardening during indentation and surface dislocation pining [33, 34]. Addition of yttria in stainless steel increases the bonding strength, density and hinders the grain growth. Finally, yttria dispersed stainless steel exhibits higher hardness than yttria free stainless steels. Yttria dispersed stainless steel show maximum hardness than yttria free stainless steel samples due to the increase in bonding strength, density and reduction in grain growth after the addition of yttria nanoparticles. The Vickers microhardness values of duplex and ferritic stainless steel sintered by SPS method
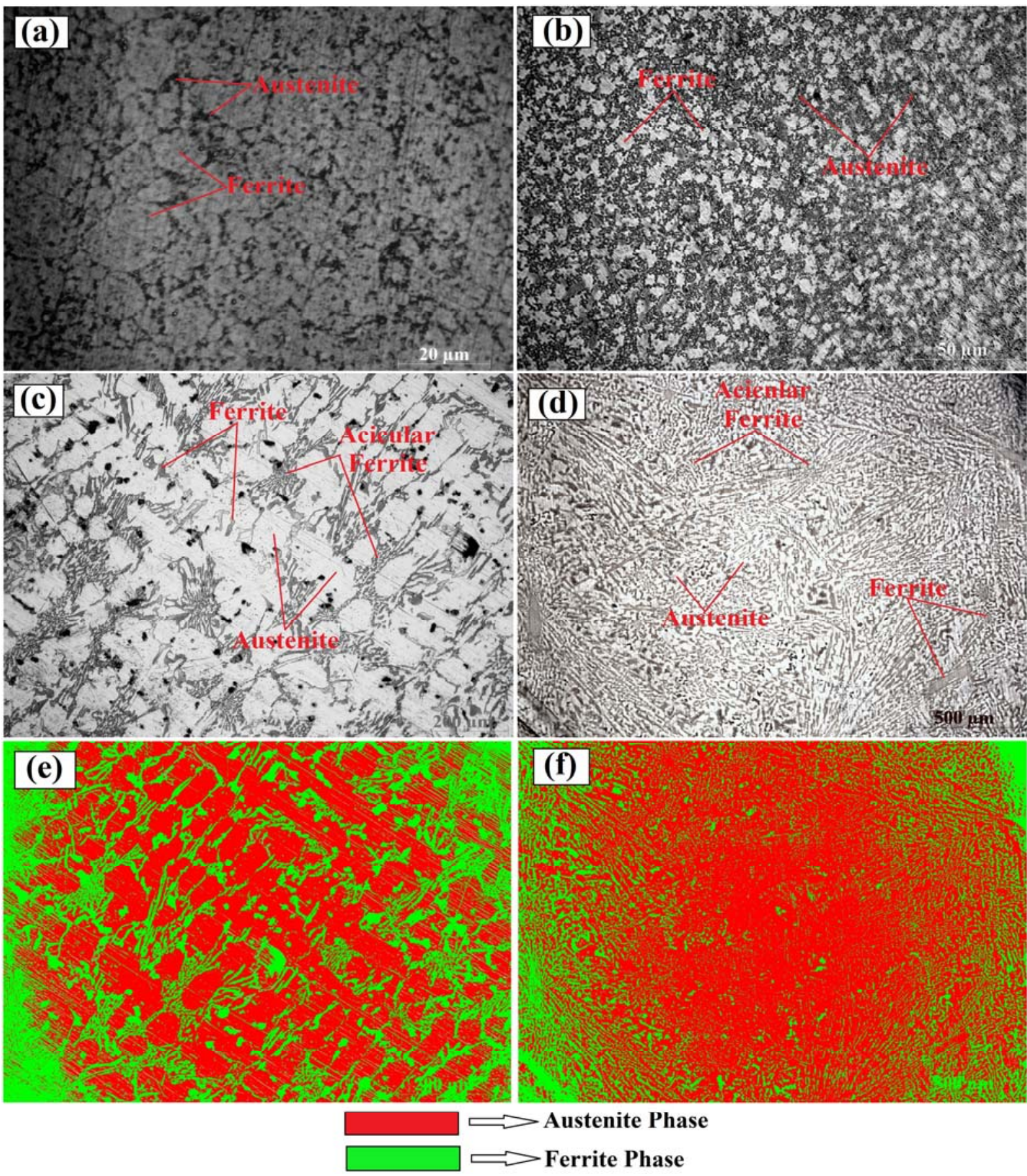

Fig. 4 Optical microstructure of (a) ferritic stainless steel (b) yttria dispersed ferritic stainless steel (c) duplex (d) yttria dispersed duplex stainless steel samples sintered at $1,000{ }^{\circ} \mathrm{C}$ by SPS method; Phase analysis of (e) duplex and (f) yttria dispersed duplex stainless steel. 

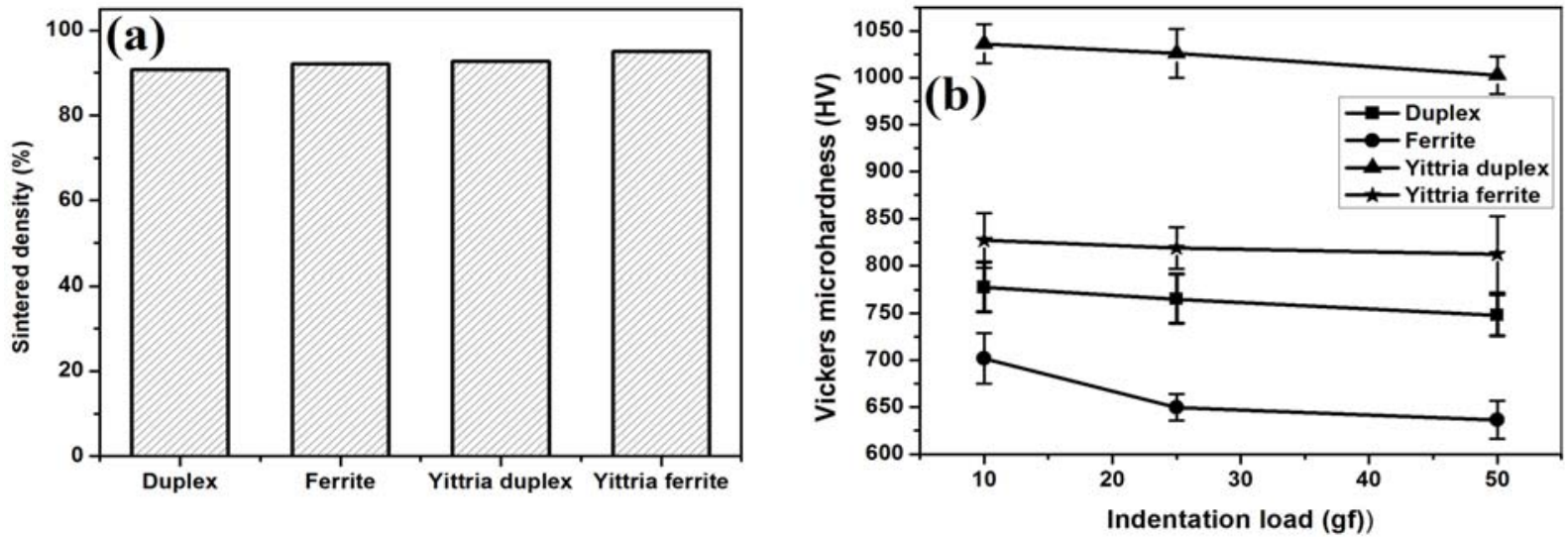

Fig. 5 Graph of (a) sintered density (b) vickers microhardness of stainless steel samples sintered at $1,000{ }^{\circ} \mathrm{C}$ by $\mathrm{SPS}$ method.

Table 1 Density and hardness of yttria dispersed and yttria free stainless steel samples sintered by SPS method at $1,000{ }^{\circ} \mathrm{C}$.

\begin{tabular}{llll}
\hline Samples & Theoretical density (\%) & Sintered density (\%) & Vickers microhardness (HV) \\
\hline Duplex stainless steel & 7.84 & 91 & 765 \\
Ferritic stainless steel & 7.75 & 92 & 650 \\
Yttria duplex stainless steel & 7.80 & 93 & 1,026 \\
Yttria ferritic stainless steel & 7.70 & 95 & 819 \\
\hline
\end{tabular}

Table 2 Stainless steel fabricated by SPS method by various researchers and comparision with present work.

\begin{tabular}{|c|c|c|c|c|c|}
\hline References & Type of stainless steel & Sintering conditions & $\begin{array}{l}\text { Sintering } \\
\text { temperature }\left({ }^{\circ} \mathrm{C}\right)\end{array}$ & $\begin{array}{l}\text { Sintered } \\
\text { density }(\%)\end{array}$ & Microhardness (HV) \\
\hline $\begin{array}{l}\text { Wei et al. } \\
{[21]}\end{array}$ & Ferritic stainless steel & $\begin{array}{l}\text { SPS in vacuum, }<6 \mathrm{~Pa} \\
\text { load for } 5 \mathrm{~min}\end{array}$ & 1,000 & 99 & 501 \\
\hline Allahar et al. [22] & $\begin{array}{l}\text { Yttria dispersed ferritic } \\
\text { stainless steel }\end{array}$ & $\begin{array}{l}\text { SPS, } 80 \mathrm{MPa} \text { load for } \\
1 \mathrm{~h}\end{array}$ & 1,050 & 97 & 380 \\
\hline $\begin{array}{l}\text { Xia et al. } \\
{[23]}\end{array}$ & ODS ferritic stainless steel & $\begin{array}{l}\text { SPS in Ar atmosphere, } \\
45 \mathrm{MPa} \text { load for } 5 \mathrm{~min}\end{array}$ & 1,050 & 97 & - \\
\hline Marnier et al. [30] & Austenitic stainless steel & $\begin{array}{l}\text { SPS in vacuum, } 50 \mathrm{MPa} \\
\text { for } 5 \mathrm{~min}\end{array}$ & 1,000 & 99.5 & 237 \\
\hline Pandey et al. [35] & $\begin{array}{l}\text { Yttria dispersed ferritic } \\
\text { stainless steel }\end{array}$ & $\begin{array}{l}\text { SPS, } 30 \mathrm{MPa} \text { load for } 5 \\
\text { min }\end{array}$ & 900 & 98 & 850 \\
\hline $\begin{array}{l}\text { Xu et al. } \\
{[36]}\end{array}$ & $\begin{array}{l}\text { Nickel free austenitic } \\
\text { stainless steel }\end{array}$ & $\begin{array}{l}\text { SPS in vacuum, } 40 \mathrm{MPa} \\
\text { load for } 8 \mathrm{~min}\end{array}$ & 1,000 & 99 & 260 \\
\hline \multirow{4}{*}{ [Present work] } & $\begin{array}{l}\text { Yttria dispersed duplex } \\
\text { stainless steel }\end{array}$ & \multirow{4}{*}{$\begin{array}{l}\text { SPS in vacuum, } 50 \mathrm{MPa} \\
\text { for } 5 \mathrm{~min}\end{array}$} & \multirow{4}{*}{1,000} & 93 & 1,026 \\
\hline & $\begin{array}{l}\text { Yttria dispersed ferritic } \\
\text { stainless steel }\end{array}$ & & & 95 & 819 \\
\hline & Duplex stainless steel & & & 91 & 765 \\
\hline & Ferritic stainless steel & & & 92 & 650 \\
\hline
\end{tabular}

at $25 \mathrm{gf}$ indentation load is $765 \mathrm{HV}$ and $650 \mathrm{HV}$ respectively. Similarly, yttria dispersed duplex and ferritic stainless steel show Vickers microhardness values of $1,026 \mathrm{HV}$ and $819 \mathrm{HV}$ respectively. Hardness and density values of yttria dispersed and yttria free stainless steel samples sintered by SPS method at $1,000{ }^{\circ} \mathrm{C}$ is tabulated in Table 1 . The present results are comparable and even hardness values are higher than results obtained by various researchers as evident in Table 2.

\subsection{Compressive Strength Study}

The compression stress-strain curve of yttria dispersed and yttria free duplex and ferritic stainless steels are studied. Fig. 6 is the representation of the compression stress-strain curve of yttria dispersed duplex stainless steel sintered at $1,000{ }^{\circ} \mathrm{C}$. Yttria dispersed duplex stainless steel exhibits the maximum 
compressive stress of 1,205 MPa and yield stress of $821 \mathrm{MPa}$.

Pasebani et al. reported that yttria dispersed stainless steel exhibits higher yield stress than yttria free stainless steel [37]. The addition of yttria increases strengthening; hardness values, forms acicular structure which acts as obstacles for dislocation motion, increases the deformation resistance, controls the recovery and re-crystallization process, inhibits the grain growth and it also increases the grain boundary strengthening [37].

\subsection{Wear Behaviour Study}

\subsubsection{Effect of Load on Wear Depth}

Figs. $7 \mathrm{a}$ and $7 \mathrm{~b}$ represent the variation of wear depth with sliding time for yttria dispersed and yttria free duplex and ferritic stainless steel measured at $40 \mathrm{~N}$ and $60 \mathrm{~N}$ applied load respectively. From Fig. 7 , it is found that increase in applied load from $40 \mathrm{~N}$ to $60 \mathrm{~N}$ increases the wear depth of all the four stainless steels. This phenomenon can be explained by using following relation:

$$
F=\mu N
$$

where, $F$ is frictional force, $N$ is normal load applied and $\mu$ is co-efficient of friction.

The Eq. (1) shows that increase in normal applied load increases the frictional force. Chowdhury et al. investigated the effect of applied load (10, 15 and 20 $\mathrm{N})$ on the friction co-efficient of stainless steel 304

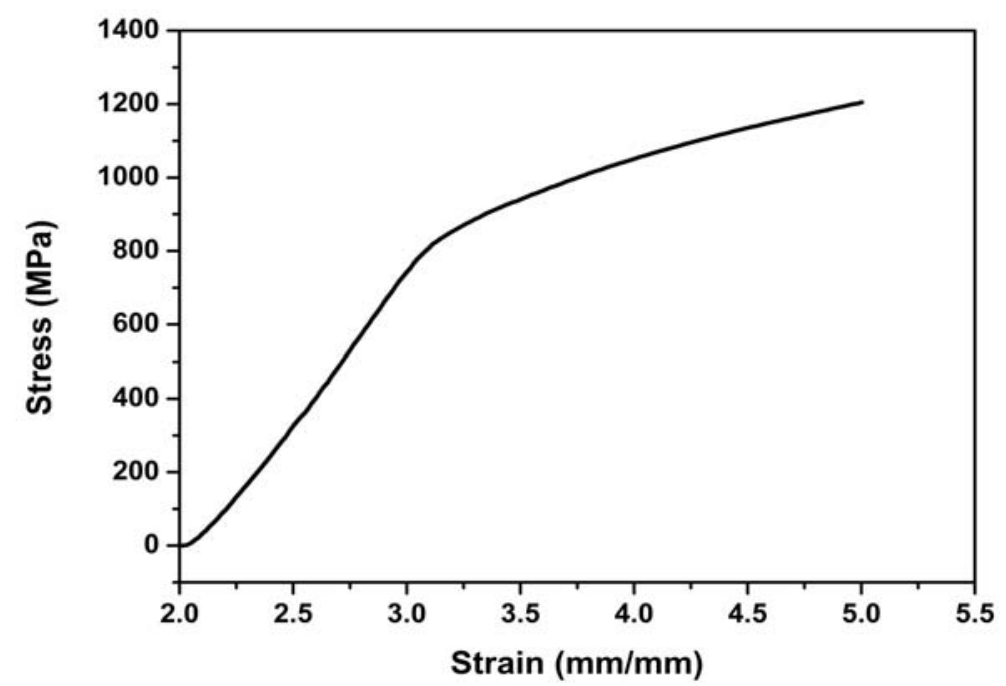

Fig. 6 Compressive stress - strain curve representation of yttria dispersed duplex stainless steel sample.
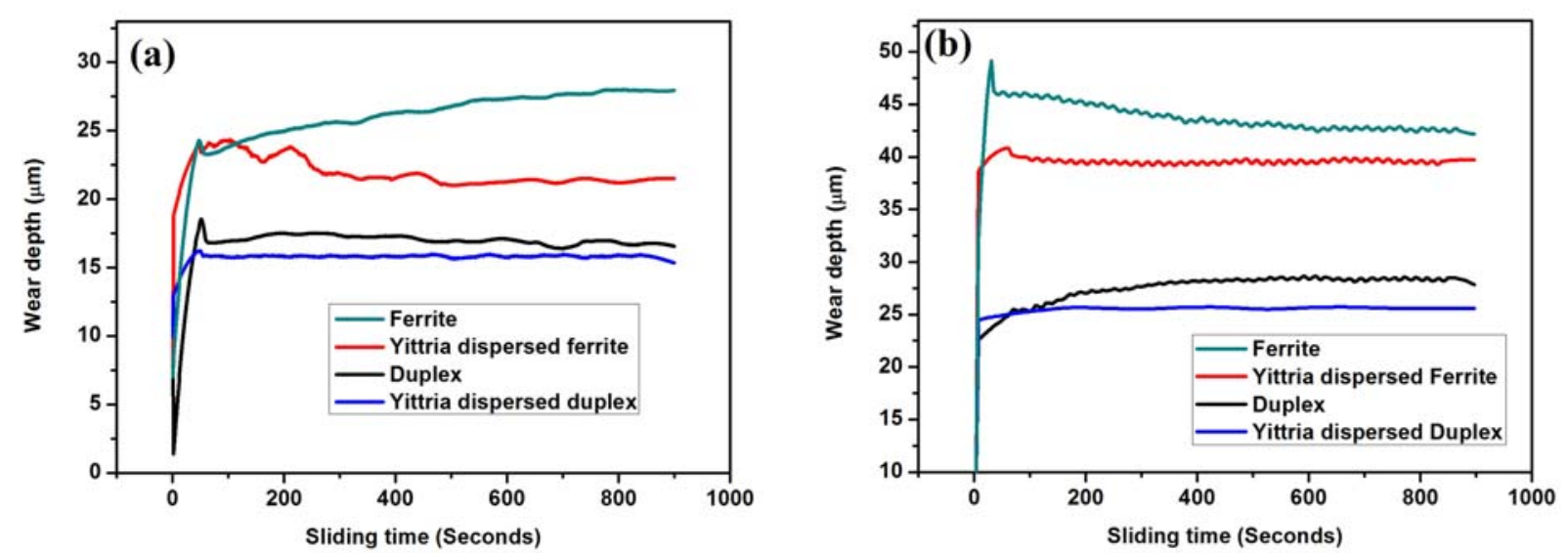

Fig. 7 Variation of wear depth of yttria dispersed and yttria free duplex and ferritic stainless steel against sliding time at a applied load of (a) $40 \mathrm{~N}$ (b) $60 \mathrm{~N}$ respectively. 
using specially designed pin on disc wear tester at 1 , 1.5 and $2 \mathrm{~m} / \mathrm{s}$ sliding velocity. They reported that co-efficient of friction decreases with the increase in applied load and it increases with increase in sliding velocity [38]. Therefore, increase in applied load increases the wear depth and thereby decreases the wear resistance as shown in the Figs. $7 \mathrm{a}$ and $7 \mathrm{~b}$.

The wear depths of duplex, ferritic, yttria duplex and yttria ferritic stainless steels at $40 \mathrm{~N}$ applied load were found to be $19,28,16$ and $24 \mu \mathrm{m}$, respectively. Similarly, the wear depths at $60 \mathrm{~N}$ applied load were found to be $29,49,26$ and $41 \mu \mathrm{m}$, respectively. We have seen that addition of yttria in stainless steel improves the density and hardness through a strong yttria-stainless steel bonding [39]. Therefore, the impingement of Rockwell indenter is less on yttria dispersed stainless steel than yttria free stainless steel. Finally, yttria dispersed stainless steel shows a lesser
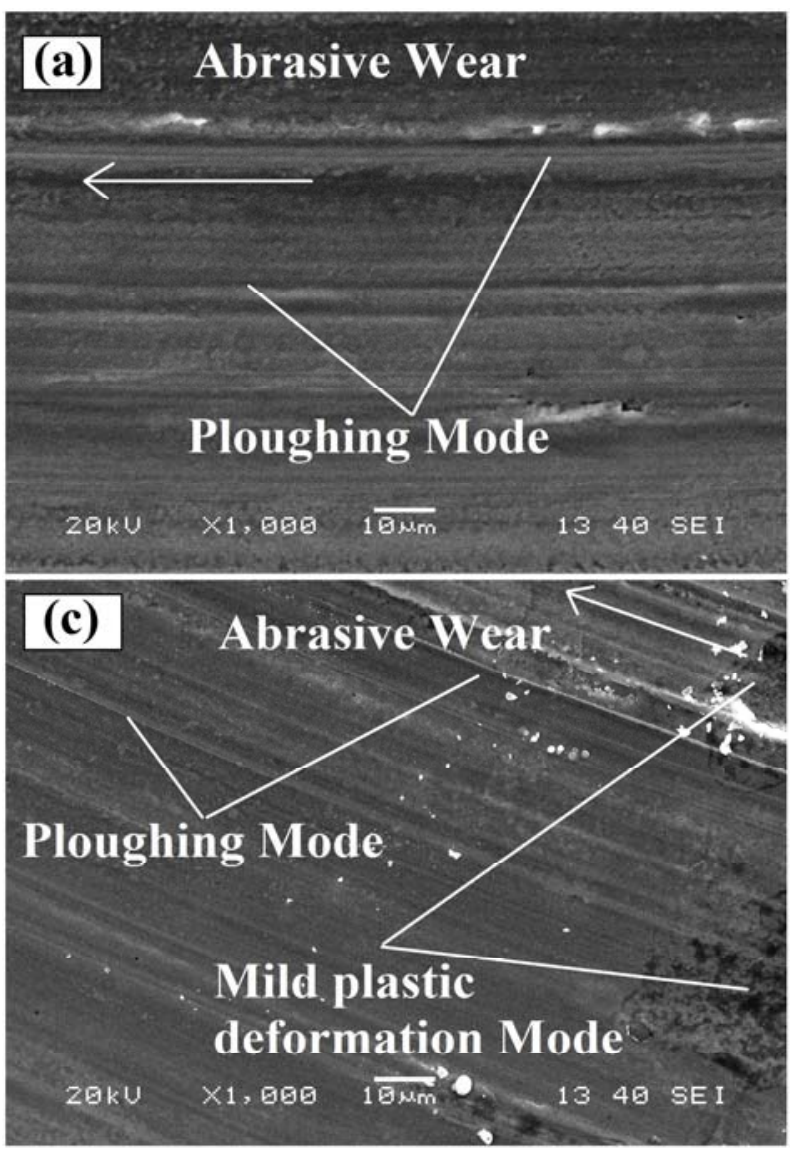

wear depth than their respective yttria free stainless steels as shown in the figure.

\subsubsection{Wear Mechanism}

The morphology of worn surface and wear debris produced by the yttria dispersed and yttria free stainless steels have been investigated using SEM to study the wear mechanism and wear modes. Figs. 8a-8d represents the SEM images of worn surfaces of yttria dispersed and yttria free duplex and ferritic stainless steel respectively tested at $40 \mathrm{~N}$.

From SEM microstructure of worn surface it is observed that all the four stainless steels follow abrasive wear mechanism with ploughing mode. The degree of ploughing depends upon the strength of the material; stronger the material, lesser will be the ploughing impression. Yttria dispersed stainless steels undergo mild ploughing compared to their respective yttria free stainless steels due to their hard
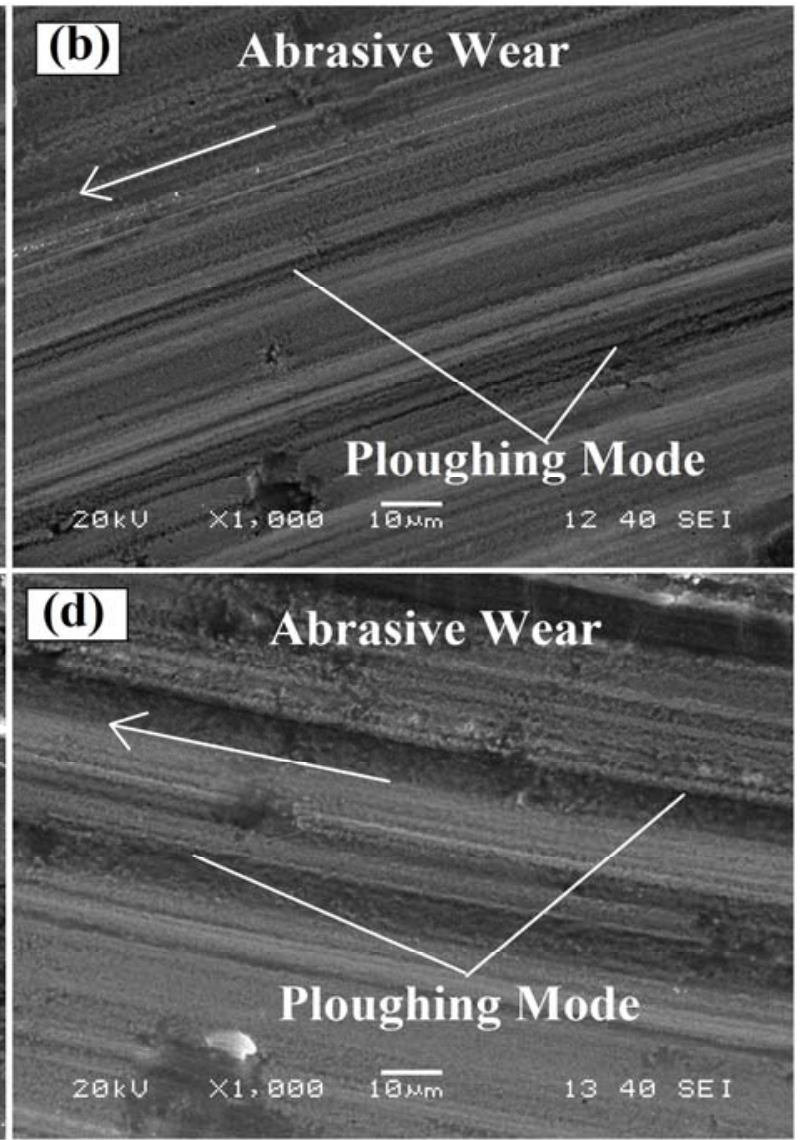

Fig. 8 SEM worn surface of (a) duplex (b) ferritic (c) yttria dispersed duplex (d) yttria dispersed ferritic stainless steel respectively at $40 \mathrm{~N}$ applied load. 
nature (confirmed by hardness study). Shashanka et al. studied the effect of added yttria nano particles on the wear resistance properties of duplex and ferritic stainless steel and they reported that, addition of yttria improves the wear properties of stainless steel [40]. On the other hand, we also investigated the effect of applied load on the morphology of worn surface.

Figs. 9a-9d represent the SEM microstructure of worn surfaces of yttria dispersed and yttria free duplex and ferritic stainless steel tested at $60 \mathrm{~N}$. From the SEM microstructure (Figs. 8 and 9), it is found that the impact of wear during $60 \mathrm{~N}$ applied load is more compared to wear during $40 \mathrm{~N}$ applied load. As seen from the micrographs that the failure is severe at $60 \mathrm{~N}$ than $40 \mathrm{~N}$ due to the high frictional force. All the stainless steel samples at a load of $60 \mathrm{~N}$ follow abrasive and mild oxidative mechanism along with ploughing and plastic deformation modes as shown in the Fig. 9. The stainless steels with maximum density and hardness undergo oxidation easily because the material worn out as small particles instead of flakes likes ductile materials. The surface area and surface energy of these small particles is more than flakes, as a result of which these wear debris undergo oxidation very easily. The produced wear debris trammel in between the two contacting surfaces and break the contacting interface to very small sizes and rapidly oxidize both wear debris and wear track surfaces [41]. Quinn [42] and Stott [43] also reported similar kind of oxidative wear mechanisms. Therefore, we performed EDS to quantify the amount of oxygen present on the wear surface. Figs. 9e-9h represent the EDS spectra of worn surfaces of duplex, ferritic, yttria dispersed duplex and yttria dispersed ferritic stainless steel at $60 \mathrm{~N}$ applied load. The oxygen percentage of duplex and yttria dispersed duplex stainless steel is found to be $15 \%$ and $17 \%$ respectively. Similarly, the oxygen percentage of ferritic and yttria dispersed ferritic stainless steel is found to be $14 \%$ and $15 \%$ respectively. The percentage of oxygen increases with the addition of yttria nanoparticles as shown in the EDS spectra.

\subsubsection{Morphology and Volume of Wear Debris} Study

Figs. 10a-10d represent the wear debris of duplex, ferritic, yttria duplex and yttria ferritic stainless steel produced at $60 \mathrm{~N}$ applied load. Duplex and yttria dispersed duplex stainless steels are hard and brittle and produce wear debris in the form of small particles with maximum surface area. But, ferritic and yttria dispersed ferritic stainless steel produce wear debris as big flake like structure due to their soft and ductile nature. Therefore, oxygen percentage of wear debris produced by ferritic and yttria dispersed ferritic stainless steel is less compared to duplex and yttria dispersed duplex stainless steel. Figs. 10e-10h represents the EDS spectra of wear debris of duplex, ferritic, yttria duplex and yttria ferritic stainless steel produced at $60 \mathrm{~N}$ applied load. The wear debris of duplex and yttria dispersed duplex stainless steel show oxygen percentage of $22 \%$ and $26 \%$ respectively. Similarly, the oxygen percentage of ferritic and yttria dispersed ferritic stainless steel is found to be $14 \%$ and $21 \%$ respectively. The volume of wear debris is very negligible at $40 \mathrm{~N}$, hence wear debris were collected at $60 \mathrm{~N}$ applied load to study the wear mechanism.

Volume of wear debris produced during wear study was calculated by Archard equation [44] as follows:

$$
Q=\frac{K W L}{H}
$$

where, $Q$ is the total volume of wear debris produced, $W$ is the total normal load, $K$ is dimensionless constant, $\mathrm{H}$ is the hardness of the softest contacting surface (original surface hardness of stainless steel) and $\mathrm{L}$ is the sliding distance. Wear debris produced depends upon the hardness of materials; higher the hardness lesser will be the volume of wear debris.

Fig. 11 depicts the volume of wear debris produced at applied load of $40 \mathrm{~N}$ and $60 \mathrm{~N}$ for all the stainless steel samples sintered at $1,000{ }^{\circ} \mathrm{C}$. From the figure it is confirmed that the volume of wear debris produced increases with increase in applied load from $40 \mathrm{~N}$ to $60 \mathrm{~N}$. 
Fabrication of Nano-Yttria Dispersed Duplex and Ferritic Stainless Steels by Planetary Milling Followed by Spark Plasma Sintering and Non-Lubricated Sliding Wear Behaviour Study
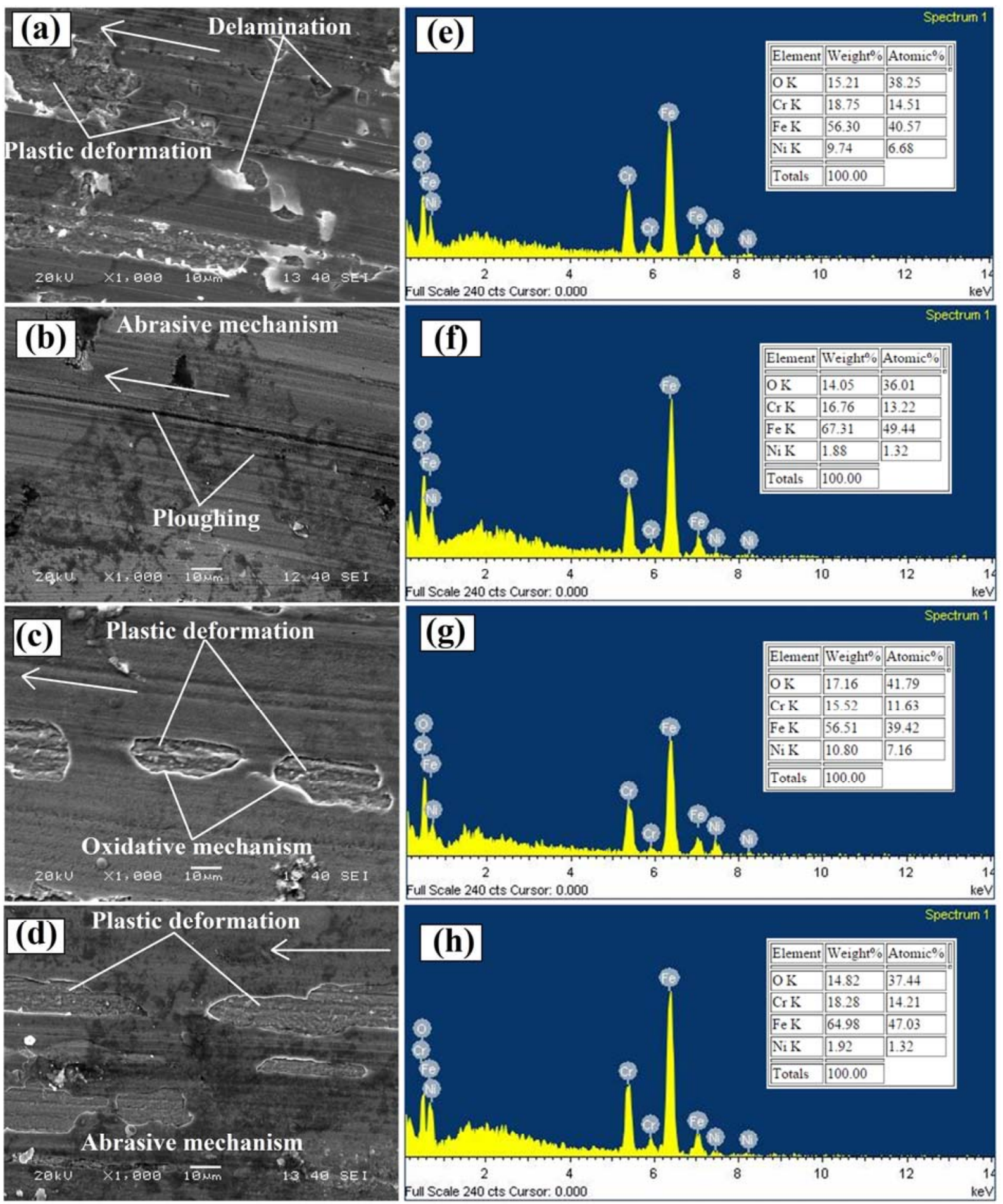

Fig. 9 SEM and EDS spectra of worn surface of (a, e) duplex, (b, f) ferritic, (c, g) yttria dispersed duplex and (d, h) yttria dispersed ferritic stainless steel respectively at $60 \mathrm{~N}$ applied load. 
Fabrication of Nano-Yttria Dispersed Duplex and Ferritic Stainless Steels by Planetary Milling Followed by Spark Plasma Sintering and Non-Lubricated Sliding Wear Behaviour Study
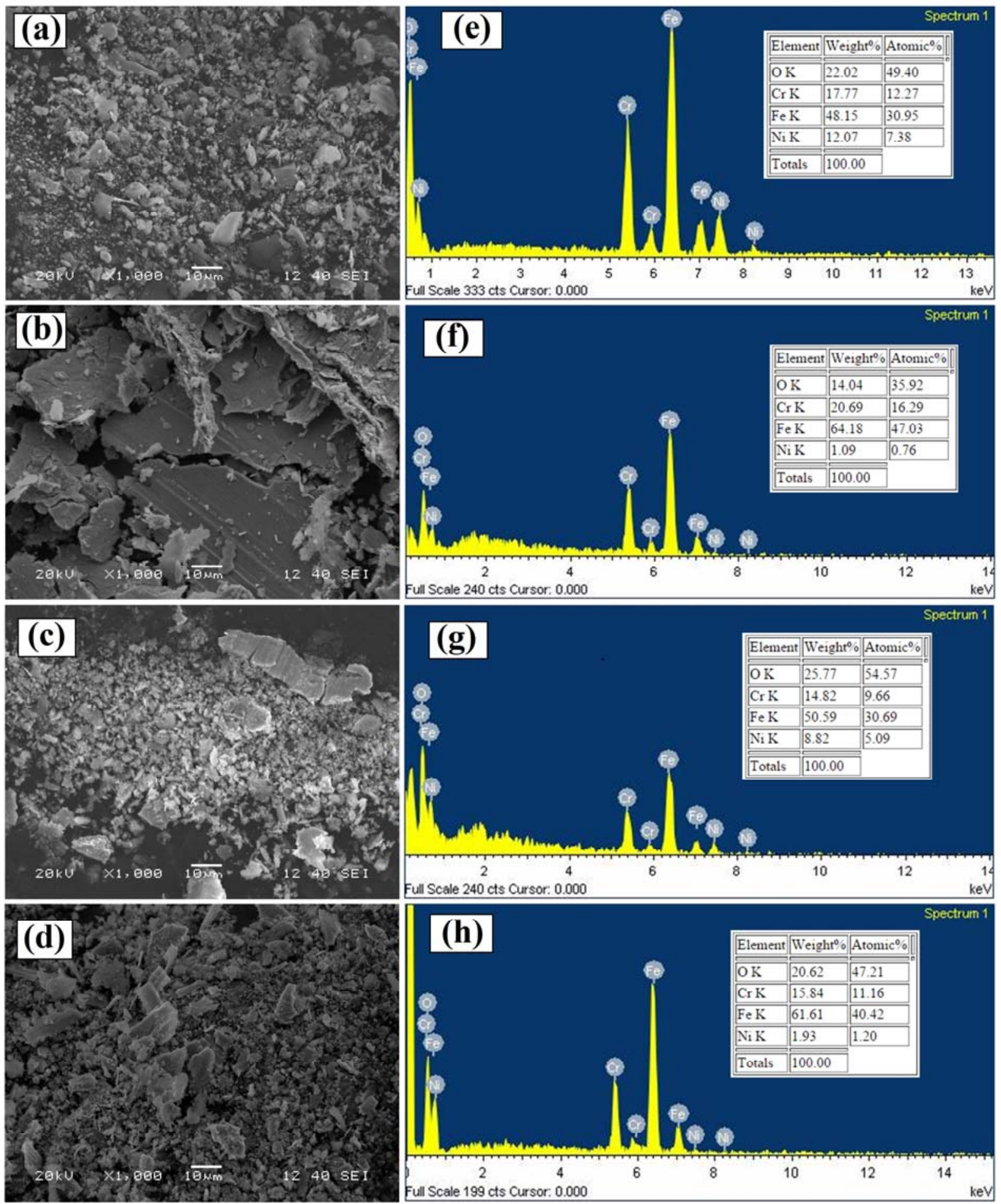

Fig. 10 SEM and EDS spectra of wear debris of (a, e) duplex, (b, f) ferritic, (c, g) yttria dispersed duplex and (d, h) yttria dispersed ferritic stainless steel respectively at $60 \mathrm{~N}$ applied load. 


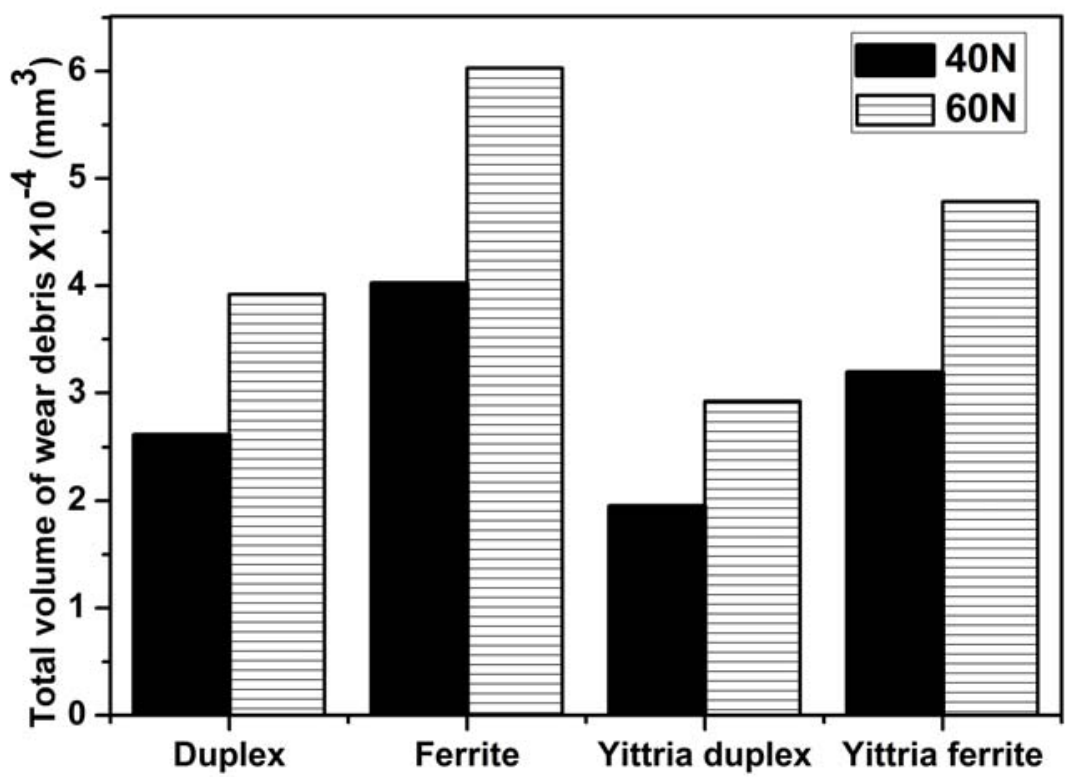

Fig. 11 The volume of wear debris produced at applied load of $40 \mathrm{~N}$ and $60 \mathrm{~N}$ for all the stainless steel samples sintered at $1,000{ }^{\circ} \mathrm{C}$.

Table 3 The values of wear depth and volume of wear debris produced by yttria dispersed and yttria free stainless steel samples at different loads.

\begin{tabular}{llclc}
\hline \multirow{2}{*}{ Type of stainless steel } & \multicolumn{2}{c}{ Wear depth $(\mu \mathrm{m})$} & \multicolumn{2}{c}{ Wear volume $\left(\mathrm{X} \cdot 10^{-4} \cdot \mathrm{mm}^{3}\right)$} \\
\cline { 2 - 5 } & $40 \mathrm{~N}$ load & $60 \mathrm{~N}$ load & 2.6 & $60 \mathrm{~N} \mathrm{load}$ \\
\hline Duplex & $19 \pm 11 \%$ & $29 \pm 9 \%$ & 4.9 & 6.0 \\
Ferrite & $28 \pm 10 \%$ & $49 \pm 8 \%$ & 1.9 & 2.9 \\
Yttria dispersed duplex & $16 \pm 8 \%$ & $26 \pm 10 \%$ & 3.2 & 4.8 \\
Yttria dispersed ferrite & $25 \pm 10 \%$ & $41 \pm 10 \%$ & & \\
\hline
\end{tabular}

Yttria free stainless steel samples produces more volume of wear debris than yttria dispersed stainless steel samples. Wang et al. [45] and Kim et al. [46] also calculated volume of austenitic stainless steel wear debris using Archard Equation and they reported that increase in applied load increases the volume of wear debris. The volume of wear debris produced by yttria dispersed and yttria free stainless steel samples at different loads are tabulated in Table 3.

\section{Conclusions}

The following conclusions can be made from the present investigation:

Yttria dispersed and yttria free duplex and ferritic stainless steel samples were fabricated efficiently by planetary milling followed by SPS.

Investigated the effect of yttria addition on the microstructure, phase transformation, density, hardness, wear and compressive stress of stainless steels.

The addition of yttria nanoparticles increases the density, hardness, wear resistance, compressive stress and favors $\alpha$-Fe to $\gamma$-Fe phase transformation.

The percentage density of duplex and yttria dispersed duplex stainless steel sintered by SPS method at $1,000{ }^{\circ} \mathrm{C}$ is found to be $91 \%$ and $93 \%$ respectively. Similarly, ferritic and yttria dispersed ferritic stainless steel possess density of $92 \%$ and $95 \%$ respectively.

The Vickers microhardness values of duplex and ferritic stainless steel sintered by SPS method at $25 \mathrm{gf}$ indentation load is $765 \mathrm{HV}$ and $650 \mathrm{HV}$ respectively. Similarly, yttria dispersed duplex and ferritic stainless steel show Vickers microhardness values of 1,026 HV and $819 \mathrm{HV}$ respectively.

Wear depth increases with increase in applied load 
from $40 \mathrm{~N}$ to $60 \mathrm{~N}$ in all the stainless steels. The wear debris produced in duplex and ferritic steel is flake shape due to soft nature, whereas particle shape wear debris is generated in case of yttria dispersed duplex steel.

\section{Acknowledgement}

Financial support for this work from the Council of Scientific \& Industrial Research (CSIR), India (Grant No. 22/561/11/EMR II Dated 11.04.2011) is gratefully acknowledged.

\section{References}

[1] Shashanka, R. and Chaira, D. 2015. "Optimization of Milling Parameters for the Synthesis of Nano-Structured Duplex and Ferritic Stainless Steel Powders by High Energy Planetary Milling." Powder Technol 278: 35-45.

[2] Shashanka, R., Chaira, D. and Kumara Swamy, B. E. 2015. International Journal of Scientific \& Engineering Research 6: 1863-1871.

[3] Shashanka, R., Chaira, D. and Kumara Swamy, B. E. 2016. International Journal of Scientific \& Engineering Research 7: 1275-85.

[4] Miyamoto, H., Mirnaki, T. and Hashimoto, S. 2001. Mater Sci Eng A 319: 779-83.

[5] Schofield, M. J., Bradsha, R. and Cottis, R. A. 2009. Mater Performance 35: 65-70.

[6] Shashanka, R., Chaira, D. and Kumara Swamy, B. E. 2015. Int J Electrochem Sci 10: 5586-98.

[7] Dobrzanski, L. A., Brytan, Z., Grande, M. A. and Rosso, M. 2007. Arch Mater Sci Eng 28: 217-23.

[8] Petterson, C. and Fager, S. 1995. Welding Practice for the Sandvik Duplex Stainless Steels SAF2304, SAF2205 and SAF2507, AB Sandvik Steel, Sweden, S811: 1-15.

[9] Smith, W. F. 1981. Structure and Properties of Engineering Alloys, 2nd ed. The University of Michigan, McGraw Hill.

[10] Liu, R. and Li, D. Y. 2000. J Mater Sci 35: 633-41.

[11] Felten, E. J. 1961. J Electrochem Soc 108: 490-5.

[12] Shashanka, R. and Chaira, D. 2015. Transactions of PMAI 41: 17-25.

[13] Francis, J. M. and Whitlow, W. H. 1965. Corros Sci 5: 701-10.

[14] Shashanka, R. and Chaira, D. 2014. Powder Technol 259: 125-36.

[15] Olaniran, O., Olubambi, P., Potgieter, J. and Adewuyi, B. 2012. J Mater Sci Technol 20: 124-32.

[16] Tokita, M. 1993. J Soc Powder Tech Jpn 30: 790-804.

[17] Omori, M. 2000. Mater Sci Eng A 287: 183-8.
[18] Kim, K. H. and Shim, K. B. 2003. Mater Character 50: 31-7.

[19] Kim, K. H., Chae, J. H., Park, J. S., Ahn, J. P. and Shim, K. B. 2009. J Ceram Process Res 10: 716-20.

[20] Dash, K., Chaira, D. and Ray, B. C. 2013. Mater Res Bull 48: 2535-42.

[21] Wei, N. H., Hang, H., Qiang, L. G. and Jing, L. 2008. J Iron Steel Res Int 15: 73-6.

[22] Allahar, K. N., Burns, J., Jaques, B., Wu, Y. Q., Charit, I., Cole, J. and Butt, D. P. 2013. J Nucl Mater 443: 256-65.

[23] Xia, Y. P., Wang, X. P., Zhuang, Z., Sun, Q. X., Zhang, T. and Fang, Q. F. et al. 2013. J Nucl Mater 432: 198-204.

[24] Gupta, S., Shashanka, R. and Chaira, D. 2015. IOP Conf. Series: Mater Sci Eng 75: 012033.

[25] Hukovic, M. M., Babic, R., Grubac, Z., Petrovic, Z. and Lajci, N. 2011. Corros Sci 53: 2176-83.

[26] Nayak, A. K., Shashanka, R. and Chaira, D. 2016. IOP Conf. Series: Mater Sci Eng 115: 012008.

[27] Tiwari, S. M., Balaji, S. and Upadhyaya, A. 2008. Mater Sci Eng A 492: 60-7.

[28] Bhadeshia., Hansraj, H. K. D., Honeycombe. and Kerr, R. W. 2006. Steels: Microstructure and Properties (3rd ed.), Butterworth-Heinemann. ISBN 978-0-7506-8084-4.

[29] Ricks, R. A., Barritte, G. S. and Howell, P. R. 1982. Proc. Int. Conf. on Solid-Solid Phase Transformations, Natural Science Foundation/Met. Soc. AIME 463-8.

[30] Marnier, G., Keller, C., Noudem, J. and Hug, E. 2014. Mater Des 63: 633-40.

[31] Shashanka, R. and Chaira, D. 2015. Mater Charact 99: 220-9.

[32] Manika, I. and Maniks, J. 2006. Acta Mater 54: 2049-56.

[33] Gong, J., Wu, J. and Guan, Z. 1999. J Eur Ceram Soc 9: 2625-31.

[34] Buckle, H. 1973. The Science of Hardness Testing and its Research Application, Westbrook, J. H. and Conrad, H., Metal Park, OH. American Society for Metals 453-94.

[35] Pandey, A., Jayasankar, K., Parida, P., Debata, M., Mishra, B. K. and Saroja, S. 2014. Powder Technol 262: 162-9.

[36] Xu, Z., Jia, C., Kuang, C., Chu, K. and Qu, X. 2009. J Alloy Compd 484: 924-8.

[37] Pasebani, S., Dutt, A. K., Burns, J., Charit, I. and Mishra, R. S. 2015. Mater Sci Eng A 630: 155-69.

[38] Chowdhury, M. A., Nuruzzaman, D. M., Roy, B. K., Dey, P. K., Mostafa, M. G. and Islam, M. S. et al. World Applied Sciences Journal 22: 1702-10.

[39] Shashanka, R. and Chaira, D. 2016. Acta Metall Sin (Engl. Lett.) 29: 58-71.

[40] Shashanka, R. and Chaira, D. 2016. Tribology Transactions, 1168897. 
Fabrication of Nano-Yttria Dispersed Duplex and Ferritic Stainless Steels by Planetary Milling Followed by Spark Plasma Sintering and Non-Lubricated Sliding Wear Behaviour Study

[41] Farias, M. C. M., Souza, R. M., Sinatora, A. and Tanaka, D. K. 2007. Wear 263: 773-81.

[42] Quinn, T. F. J. 1983. Tribol Int 16: 257-71.

[43] Stott, F. H. 1998. Tribol Int 31: 61-71.

[44] Archard, J. F. and Hirst, W. 1956. P Roy Soc Lond A Mat
236: 397-410.

[45] Wang, B., Yao, B. and Han, Z. 2012. J Mater Sci Technol 28: 871-7.

[46] Kim, H., Choi, J. H., Kim, J. K., Hong, H. S. and Kim, S. J. 2003. J Alloy Compd 351: 309-13. 